\title{
Evaluation of the effectiveness of implementing production logistics automation systems supported by computer simulation tools
}

\author{
Dariusz Więcek ${ }^{1, *}$, Dorota Więcek ${ }^{1}$, Ivan Kuric $^{1}$, Monika Bučková $^{2}$ and Martin Krajčovič ${ }^{2}$ \\ ${ }^{1}$ University of Bielsko-Biała, Willowa 2, 43-309 Bielsko-Biała, Poland \\ ${ }^{2}$ University of Zilina, Univerzitná 1, 01026 Zilina, Slovakia
}

\begin{abstract}
In this article, authors described selected logistics automation tools (ASLP) and briefly presented the PROMETHEE multi-criteria decision making method in terms of its application in assessing the implementation of ASLP in the field of production logistics. A methodology for preparing the data required to evaluate the ASLP implementation process based on modelling and simulation tools was also proposed.
\end{abstract}

\section{Introduction}

In the current economic conditions in the area of production logistics, it is required to implement tools to increase economic competitiveness, which can be the difference between profit and loss [1]. Literature review in the field of implementation of logistics automation systems in manufacturing is related to such issues as: company value increase, profit, return on investment, integration with other systems, implementation cost, and the influence of the human factor during systems implementation and functioning. Moreover, the literature contains elaborations of pilot implementations from the point of view of analysis of specific cases. The research usually considers the conditionings of particular enterprises or processes [2]. The research by some authors analysed the advantages of implementing automatic identification systems, decreasing manufacturing costs, storing costs and other production processes costs during analysis of investment return related to implementation ASLP [3]. The analyses seem to be based on very complicated mathematical models, which make them inapplicable during managerial decision making process. Also, there have been many studies using qualitative assessment methods related to different cases of applying ASLP. Another group of elaborations are reports created by manufacturers and integrators of ASLP solutions. For the purpose of taking investment and implementation decisions, these materials may be a source of too optimistic data [4].

When analysing literature, it's also possible to notice some problems with determining advantages of ASLP implementation in manufacturing on the basis of the tools and methods presented so far in the publications.

\footnotetext{
* Corresponding author: wiecekd@ath.bielsko.pl
} 
In this situation, there is a need of preparing a methodology of assessing different ASLP solutions in different organizational, technical and financial conditions. A vital element of such a methodology is determination of assessment criteria for the decision makers.

\section{Multi-criteria evaluation of implementing logistics automation systems in manufacturing}

A problem of multi-criteria evaluation comes down to determining the best decision in a discreet set of decisions with n number of elements (the set is countable and finite $\left\{\boldsymbol{D}_{i}\right\}$ ). A decision in the research is understood as one of the implementation variants in the analysed production system of ASLP tools. Each variant in the set is evaluated on the basis of criteria $\boldsymbol{K}$, and in particular for each criterion we are looking for the best variant evaluation (so we assume the search direction as maximum) [5]. A very important aspect of multi-criteria evaluation is the determination of evaluation measures. In a general case we assume that evaluation measures for variants should be expressed quantitatively, which means that evaluation criteria are measurable. If a criterion is not measurable (qualitative) in a decision problem, it is possible to apply a set of ranks instead of qualitative measures, e.g. Spearman's rank correlation coefficient or to use a method of evaluation which accepts qualitative measures, e.g. the PROMETHE; AHP [6,7].

\subsection{Determining a set of criteria}

From the point of view of productivity of manufacturing systems, Lean Manufacturing philosophy aims to limit waste on each stage of the production process by implementing simple improvements, and reasonable investment projects. In such a situation, evaluation criteria are just the losses present in the production process. Taiichi Ōhno in 1978 drew up a classic list of seven types of waste in a production plant [8]:

- waste of overproduction;

- waste of inventory;

- waste of defects;

- waste of waiting;

- waste of over-processing;

- waste of transportation;

- waste of motion.

In the Lean Manufacturing philosophy, 8 waste Non-Utilized Talent - Employees that are not effectively are considered. Due to the non-deterministic nature of this waste from the point of view of production logistics processes, it was not adopted as an assessment criterion.

Causes of Ohno's 7 types of waste in non-automated logistic systems were presented in table 1 .

Table 1. Causes of Ohno's 7 types of waste in non-automated logistic systems.

\begin{tabular}{|c|c|c|}
\hline Type of waste & Cause of waste & Measurement unit \\
\hline Over-production & $\begin{array}{c}\text { Difference between physical flow and } \\
\text { information flow leading to incoherence of } \\
\text { inventory levels }\end{array}$ & $\begin{array}{c}\text { Number of product } \\
\text { units }\end{array}$ \\
\hline Waiting & $\begin{array}{c}\text { More time spent for collecting data and } \\
\text { correcting mistakes }\end{array}$ & Time \\
\hline Transportation & $\begin{array}{c}\text { Faulty data cause transportation in a wrong } \\
\text { place }\end{array}$ & Time \\
\hline
\end{tabular}




\begin{tabular}{|c|c|c|}
\hline Type of waste & Cause of waste & Measurement unit \\
\hline Over-processing & $\begin{array}{c}\text { Wrongly identified product is improperly } \\
\text { processed and Leeds to waste of time }\end{array}$ & Time \\
\hline Inventory & $\begin{array}{c}\text { WIP rises by imprecise determination of the } \\
\text { number of processed elements. }\end{array}$ & $\begin{array}{c}\text { Number of product } \\
\text { units }\end{array}$ \\
\hline Motion & Performing activities that can be automated & Time \\
\hline $\begin{array}{c}\text { Faults and quality } \\
\text { defects }\end{array}$ & $\begin{array}{c}\text { A wrongly identified product is improperly } \\
\text { processed; is subject to improper quality } \\
\text { control. In fact, it should be scraped. }\end{array}$ & $\begin{array}{c}\text { Number of scraped } \\
\text { product units }\end{array}$ \\
\hline
\end{tabular}

\subsection{A general workflow by evaluating variants of ASLP implementation}

In order to find the ASLP implementation variant with the highest functional features for the given production system, it is necessary to generate a set of data presented in table 2 . The most significant element of the above procedure is to determine measures of criteria evaluation, that is, in a given case, the values of losses in the production process when implementing particular ASLP variant. This type of empirical data is very difficult to determine on an early stage of selecting an implementation variant. In such a case, modelling and simulation tools should be used, which allow to estimate the necessary values.

Table 2. Causes of Ohno's 7 types of waste in non-automated logistic systems

\begin{tabular}{|c|c|c|c|c|c|c|c|c|}
\hline \multicolumn{2}{|c|}{ Main criteria } & $\begin{array}{c}\text { Over- } \\
\text { production }\end{array}$ & Waiting & $\begin{array}{c}\text { Trans- } \\
\text { portation }\end{array}$ & $\begin{array}{c}\text { Over- } \\
\text { processing }\end{array}$ & $\begin{array}{l}\text { Inven- } \\
\text { tory }\end{array}$ & Motion & $\begin{array}{c}\text { Faults } \\
\text { and } \\
\text { quality } \\
\text { defects }\end{array}$ \\
\hline \multicolumn{2}{|c|}{$\begin{array}{l}\text { Optimization } \\
\text { direction }\end{array}$} & $\min$ & $\min$ & $\min$ & $\min$ & $\min$ & $\min$ & $\min$ \\
\hline \multicolumn{2}{|c|}{$\begin{array}{c}\text { Criterion } \\
\text { weight }\end{array}$} & $w^{(l)}$ & $w^{(2)}$ & $w^{(3)}$ & $w^{(4)}$ & $w^{(5)}$ & $w^{(6)}$ & $w^{(7)}$ \\
\hline \multicolumn{2}{|c|}{$\begin{array}{l}\text { Generalized } \\
\text { criterion }\end{array}$} & $\boldsymbol{P}^{(l)}$ & $P^{(2)}$ & $P^{(3)}$ & $P^{(4)}$ & $P^{(5)}$ & $P^{(6)}$ & $P^{(7)}$ \\
\hline \multicolumn{2}{|c|}{$\begin{array}{c}\text { Indifference } \\
\text { threshold }\end{array}$} & $\omega^{(l)}$ & $\omega^{(2)}$ & $\omega^{(3)}$ & $\omega^{(4)}$ & $\omega^{(5)}$ & $\omega^{(6)}$ & $\omega^{(7)}$ \\
\hline \multicolumn{2}{|c|}{$\begin{array}{c}\text { Preference } \\
\text { threshold }\end{array}$} & $\pi^{(l)}$ & $\pi^{(2)}$ & $\pi^{(3)}$ & $\pi^{(4)}$ & $\pi^{(5)}$ & $\pi^{(6)}$ & $\pi^{(7)}$ \\
\hline \multirow{6}{*}{ 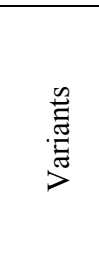 } & \multicolumn{8}{|c|}{ Evaluation measures for variants $\left(v_{i}{ }^{(k)}\right)$} \\
\hline & $D_{1}$ & $v_{1}^{(I)}$ & $v_{1}^{(2)}$ & $v_{1}^{(3)}$ & $v_{1}^{(4)}$ & $v_{1}^{(5)}$ & $v_{1}^{(6)}$ & $v_{1}^{(7)}$ \\
\hline & $D_{2}$ & $v_{2}^{(I)}$ & $v_{2}^{(2)}$ & $v_{2}^{(3)}$ & $v_{2}^{(4)}$ & $v_{2}^{(5)}$ & $v_{2}^{(6)}$ & $v_{2}{ }^{(7)}$ \\
\hline & $\begin{array}{l}\ldots \\
D_{i}\end{array}$ & $\frac{\ldots}{v_{v}{ }^{(l)}}$ & $\ldots$ & $\begin{array}{c}\ldots \\
\ldots \\
p^{(3)}\end{array}$ & $\begin{array}{c}\ldots \\
\ldots \\
p^{(4)}\end{array}$ & $\frac{}{\ldots}$ & $\ldots$ & $\ldots$ \\
\hline & $\begin{array}{l}\boldsymbol{D}_{i} \\
\ldots \ldots\end{array}$ & $\begin{array}{c}\boldsymbol{D}_{i} \\
\ldots \ldots\end{array}$ & $\begin{array}{c}v_{i} \\
\ldots \ldots\end{array}$ & $\begin{array}{l}\boldsymbol{D}_{i} \\
\ldots \ldots\end{array}$ & $\begin{array}{l}\boldsymbol{D}_{i} \\
\ldots \ldots\end{array}$ & $\begin{array}{c}\theta_{i} \\
\ldots \ldots\end{array}$ & $\begin{array}{l}\boldsymbol{D}_{i} \\
\ldots \ldots\end{array}$ & $\begin{array}{l}\delta_{i} \\
\ldots \ldots\end{array}$ \\
\hline & $D_{n}$ & $\bar{v}_{n}{ }^{(I)}$ & $v_{n}{ }^{(2)}$ & $v_{n}{ }^{(3)}$ & $\boldsymbol{v}_{n}{ }^{(4)}$ & $\bar{v}_{n}{ }^{(5)}$ & $\bar{v}_{n}{ }^{(6)}$ & $v_{n}{ }^{(7)}$ \\
\hline
\end{tabular}

\section{Application of simulation methodology in generating measures for variants}

A simple example of a production logistics system with semiautomatic picking zones was modelled to present the application possibilities of dynamic simulation methodology in generating measures for the variants. An example production logistics system was modelled in the Tecnomatix Plant Simulation software, as part of research at the Department of Industrial Engineering of the University of Zilina. Figure 1 shows the visualization of the $2 \mathrm{~d}$ and $3 \mathrm{~d}$ models [9]. 


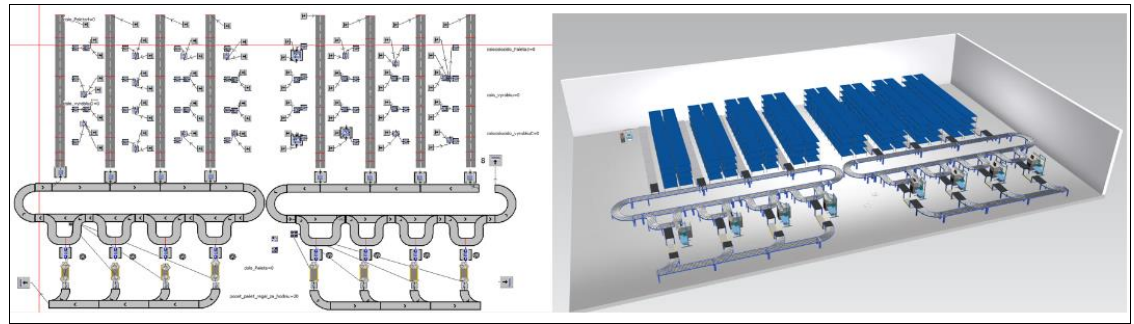

Fig. 1. Example of simulation model of zone picking.

In simulation tests it is possible to verify the assumed system parameters, which are a set of input values affecting the received simulation parameters. In simulation experiments, several simulation cycles are carried out at constant input values and output values are generated based on the assumed parameters. The software randomly changed the set values. It was assumed that the logistics system behaves stochastically, so the model must generate parameters according to various probability distributions, which may give unpredictable results. The ability to present the results of the experiment in the form of tables and graphs allows for proper interpretation of the obtained results [9]. Fig. 2 shows the level of employee utilization and examples of activities that they performed during the assembly of components. Fig. 2 a) shows that, on average, employees spent $70.3 \%$ of the time on transporting and handling components, $27.7 \%$ on waiting for a transport trolley and $2 \%$ on other activities. Fig. 2 b) presents a column chart based on which we can determine when employee activity increases or decreases. It can also be stated that employee activity always increases selectively, and gradually decreases during system overload. Basing on the sets presented in Figure 2, it is possible to determine the value of the "waste of waiting" evaluation criterion for various input parameters of the simulation process. It is important that from the graph in figure 2 you can specify the value of one of the Waiting criterion for different input parameters of the simulation process.

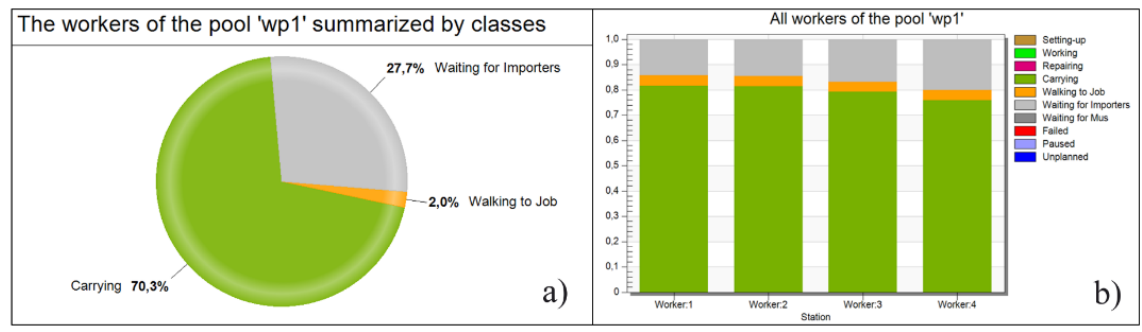

Fig. 2. Employee activity chart a) full pie chart of employee work, b) column chart of 4 employees in the modelled picking area.

To minimize unnecessary motion (waste of motion), you can apply the graphic simulation methodology for the manipulator and transporter paths described in [10] and the methodology for optimizing transport routes presented in [11] for minimize waste of transportation.

\section{Summary and directions for further research}

Thanks to analysing the literature related to identification in resources in delivery chains, it was possible to draw the following conclusions that warehouse management (identification, labelling and tracking products) be means of the barcode technology causes time losses, resulting from the need of manual data reading. 
In order to be able to determine the influence of different logistics automation systems on the elimination of waste in the production process, it is necessary to determine the tools which allow illustrating their influence on particular waste types. The tools would also allow to conduct a simulation of the influence of different ASLP implementation variants on limiting the waste in the process. This influence can be analysed in three areas:

- Collection of data on the course, elements and participants of the production process;

- Verification of the accuracy of the collected data;

- Identification of the influence of the collected data on the analysed waste.

In order to achieve the desired research results, the methodology which allows to systematize further research should be used. The proposed methodology includes five steps:

\section{Step 1: Investigating the production process and a chance for logistics automation}

Process modelling: conducting an analysis of the production system to be automated by using process mapping tools, value stream mapping.

Analysis of automation implementation possibility: this stage should consist of production process analysis from the point of view of ASLP implementation by means of mapping tools. This analysis will be a basis for determining the waste which is sensitive to implementing different ASLP elements. A set of mapping tools is presented in table 3.

Table 3. Mapping tools for identifying waste in the production process

\begin{tabular}{|c|c|c|}
\hline Mapping tool & Waste & Waste identification \\
\hline $\begin{array}{c}\text { PPM (Physical } \\
\text { Process Map- } \\
\text { ping) }\end{array}$ & Unnecessary \\
transport & $\begin{array}{c}\text { UCD (UML } \\
\text { Use-Case Dia- } \\
\text { gram) }\end{array}$ & $\begin{array}{c}\text { Specifies storage locations data, location data informing } \\
\text { about unnecessary movement of operators and products. }\end{array}$ \\
\cline { 3 - 3 } DDD (Data & $\begin{array}{c}\text { Shows use cases defined for the analysed system and } \\
\text { elements involved in the functioning of the system. It } \\
\text { can be used to determine which parts of the process are } \\
\text { carried out by means prone to errors. }\end{array}$ \\
$\begin{array}{c}\text { Dependency } \\
\text { Diagram) }\end{array}$ & $\begin{array}{c}\text { Wuality defects and } \\
\text { faults, overproduc- } \\
\text { tion, inventory, over- } \\
\text { processing }\end{array}$ & $\begin{array}{c}\text { It determines the decision points of the process on the } \\
\text { basis of which it is possible to draw conclusions which } \\
\text { processes affect certain errors. Determines the level of } \\
\text { concurrency of operations and whether the speed of the } \\
\text { process will improve if it is automated. }\end{array}$ \\
\hline $\begin{array}{c}\text { DataVis (Data } \\
\text { Visibility) }\end{array}$ & $\begin{array}{c}\text { Overproduction, } \\
\text { inventory }\end{array}$ & $\begin{array}{c}\text { It allows visualizing the level of impact of process } \\
\text { parameters on batch size, work in progress (WIP) or } \\
\text { finished production. }\end{array}$ \\
\hline $\begin{array}{c}\text { PRA (Produc- } \\
\text { tion responsive- } \\
\text { ness approach) }\end{array}$ & All & $\begin{array}{c}\text { It examines the impact of disturbances on the efficiency } \\
\text { of the logistics process, helps determine current capaci- } \\
\text { ties and their use to prevent disturbances. It allows you } \\
\text { to check whether SALP technologies can help improve } \\
\text { process efficiency. }\end{array}$ \\
\hline
\end{tabular}

Step 2: Modelling the current condition of processes: after determining the production process stages and the waste to be minimized thanks to ASLP implementation, the next step is to model the current condition of the process. Irrespective of which simulation tools will be used for particular tasks, it's necessary to determine their basic parameters, i.e. time, probability of realizing different activities in the process, inputs and outputs to the process.

Step 3: Modelling the future shape of processes: the next step is to build a model of the future state of the process after ASLP implementation. Different ASLP variants may by analysed in different configurations and on different integration levels.

Step 4: Sensitivity analysis: sensitivity analysis (SA) is a study of how variability (uncertainty) at the output of a simulation model depends on the variability of parameter values at the input of the model [12]. Probability of mistakes in a model of the current 
process shape due to improper data register is a reference point for assessing improvement in different ASLP variants in the area of reduction of the seven types of waste. A very important element of sensitivity analysis of some types of waste is the influence of system variables on processes costs. In this area, cost estimation methods should be taken into account. Determination of future costs of functioning for different ASLP variants may be conducted on the basis of the assumptions of generative cost estimation methodology [13].

Step 5: ASLP assessment based on multi-criteria decision making methods: on this stage, on the basis of the data collected during previous steps, assessment of particular logistics automation systems is conducted individually or in different configurations. The assessment should be made on the basis of common criteria, which, in case of lean manufacturing, should be the reduction measures of Ohno's 7 types of waste.

\section{References}

1. N. S. Ungureanu, A. Petrovan, and M. Ungureanu, Contributions to the Development of an Ontology in Logistics of Manufacturing, Springer, Cham, pp.299-306, (2019)

2. G. Kłosowski, A. Gola, and T. Amila, Computational Intelligence in Control of AGV Multimodal Systems, IFAC-PapersOnLine, vol. 51, no. 11, pp. 1421-1427, (2018).

3. P. Oghazi, F. Fakhrai Rad, S. Karlsson, and D. Haftor, RFID and ERP systems in supply chain management, European Journal of Management and Business Economics, vol. 27, no. 2, pp. 171-182, (2018).

4. K. Domdouzis, B. Kumar, and C. Anumba, Radio-Frequency Identification (RFID) applications: A brief introduction, Advanced Engineering Informatics, vol. 21, no. 4, pp. 350-355, (2007).

5. R. Drobina, A. Włochowicz, and M. S. Machnio, Multi-Criterion Assessment of Pneumatically Spliced Cotton Combed Ring-Spun Yarns, Fibres and Textiles in Eastern Europe. vol. 16, pp. 25-32, (2008).

6. A. B. Maulachela et al., Promethee: As a supporting decision of selection of poor rice receivers, Journal of Physics: Conference Series, vol. 1211, no. 1, (2019).

7. D. Miszczyńska, Wielokryteriowy ranking Otwartych Funduszy Emerytalnych metodami AHP i PROMETHEE, 166th ed. Łódź: Acta Universitatis Lodziensis. Folia Oeconomica, (2003).

8. T. Ohno, System produkcyjny Toyoty: więcej niż produkcja na duża skale, ProdPress, Warszawa, (2008).

9. M. Bučková, M. Krajčovič, and D. Plinta, Use of Dynamic Simulation in Warehouse Designing, Springer, Cham, pp. 485-498, (2019).

10. O.A. Deteşan, F. Bugnar, A. Trif, and C. M. Nedezki, The path planning of TRR smallsized robot, Acta Technica Napocensis - series: Applied Mathematics, Mechanics, and Engineering, vol. 59, no. 3, pp. 279-284, (2016).

11. D. R. Delgado Sobrino, O. Moravcik, D. Caganová, and P. Kostal, Hybrid Iterative Local Search Heuristic with a Multiple Criteria approach for the vehicle routing problem, Advanced Materials Research, vol. 383-390, pp. 4560-4567, (2012).

12. A. Saltelli et al., Why so many published sensitivity analyses are false: A systematic review of sensitivity analysis practices, Environmental Modelling and Software, vol. 114, pp. 29-39, (2019).

13. D. Więcek and D. Więcek, Production costs of machine elements estimated in the design phase, Advances in Intelligent Systems and Computing, vol. 637, pp. 380-391, (2018). 